\title{
AVALIAÇÃO DA EFICÁCIA DO ANTIVENENO BOTRÓPICO ADMINISTRADO NO LOCAL DA INOCULAÇÃO INTRAMUSCULAR DO VENENO DE BOTHROPS JARARACA: ESTUDO EXPERIMENTAL EM CAMUNDONGOS
}

\author{
Carla Lilian AgOSTINI UTESCHER (1), Silvia Lucia Paro VIEIRA (1), Sara FenSTERSEIfER (1), \\ Lindioneza Adriano RIBEIRO (2) \& Miguel Tanús JORGE (3).
}

\begin{abstract}
RESUMO
Foi determinada, em camundongos de 18 a $20 \mathrm{~g}$, a dose efetiva $50 \%$ do antiveneno botrópico, por via intraperitoneal (ip), imediatamente (DE50 Oh) e 30 minutos (DE50 30') após a inoculação de 2 DL50 do veneno de $B$. jararaca, por via intramuscular (im). A DE50 $30^{\prime}$ foi três vezes maior do que a DE50 Oh. A eficácia do antiveneno administrado no local da inoculação do veneno foi avaliada inoculando-se duas DL50 do veneno, por via im, e administrando-se a DE50 do antiveneno imediatamente (DE50 Oh) e 30 minutos após (DE50 30'), de duas formas a saber: totalmente por via ip (1") e metade por via ip e metade por via im $\left(2^{\mathrm{a}}\right)$, no mesmo local da inoculação do veneno. 0 antiveneno ofereceu, por via ip, maior proteção aos camundongos (menor taxa de óbito em 48 horas) do que quando metade do mesmo foi administrado, por via im, no local da inoculação do veneno. Conclui-se que, neste modelo experimental, quando se inicia o tratamento tardiamente há necessidade de maior dose de antiveneno botrópico e que não há beneficio em administrá-lo no local da picada.
\end{abstract}

UNITERMOS: Bothrops jararaca; Veneno; Antiveneno; DL50: DE50.

\section{INTRODUÇÃo}

No início deste século, poucos anos após a produção por Calmette (Paris - 1886) do primeiro soro heterólogo para uso terapêutico no envenenamento por serpente (Naja naja), Vital Brazil produziu, em São Paulo (Instituto Butantan), soros heterólogos contra venenos de Bothrops jararaca e Crotalus durissus terrificus ${ }^{2,4}$. Nesta ocasião recomendou sua utilização por via subcutânea (sc). Em publicação de 1949, FONSECA recomendou, em alguns casos, a inoculação do soro no local da picada ${ }^{3}$. ROSENFELD, entretanto, contra-indicou este procedimento em caso de acidente por Bothrops por considerar que ocorreria aumento da incidência de necrose ${ }^{12}$.

Em 1981, publicação da Organização Mundial de Saúde recomendou a administração do antiveneno por via endovenosa (ev) ${ }^{14}$. Recentemente, no Brasil, as publicações oficiais têm recomendado a administração dos soros antiofidicos, preferencialmente, apenas por via ev ${ }^{7,13}$. Como os venenos botrópicos e crotálicos têm

Trabalho realizado na Seção de Controle de Qualidade do Instituto Butantan.

Dados parcialmente apresentados no IV ${ }^{\mathrm{b}}$ Pan American Symposium on Animal, Plant and Microbial Toxins and IInd Symposium of the Brazilian Society on Toxinology. Campinas - SP, Brazil, 1992.

(1) Seção de Controle de Qualidade do Instituto Butantan, São Paulo.

(2) Centro de Vigilância Epidemiológica (Comissão Permanente de Coordenação para o Controle dos Acidentes por Animais Peçonhentos), São Paulo.

(3) Departamento de Clínica médica do Centro de Ciências Biomédicas da Universidade Federal de Uberlândia, Minas Gerais.

Endereço para correspondência: Miguel Tanús Jorge, Departa mento de Clínica Médica, Universidade Federal de Uberlândia. Av. Pará 1720, Campus Umuarama CEP 38400-902, Uberlândia, MG, Brasil. 
maior probabilidade de serem inoculados na vítima humana por via intramuscular (im) e/ou sc, uma vez que Bothrops e Crotalus são serpentes solenóglifas, recentemente se testou, em camundongos, a eficácia da administração do antiveneno crotálico por via im, no mesmo local da inoculação também im do veneno de $C$. $d$. terrificus. Observou-se que a administração de todo o soro por via ip levava a melhores resultados do que quando parte do soro era administrada no local da inoculação da peçonha ${ }^{9}$.

A intensa destruição tecidual, tromboses de pequenos vasos e hemorragias que ocorrem no envenenamento botrópico ${ }^{5,6,12}$, entretanto, podem dificultar a absorção do veneno e a difusão do soro administrado por via ev ou ip.

O presente trabalho pretende avaliar, em camundongo, a eficácia da administração do soro antibotrópico por via im, no mesmo local da inoculação, também im, do veneno de $B$. jararaca.

\section{MATERIAL E MÉTODO}

\section{Material}

Veneno referência de $B$. jararaca produzido pelo Instituto Butantan (IB), distribuido pelo Instituto Nacional de Controle de Qualidade em Saúde (INCQS), com DL50 de 77,00 $\mu \mathrm{g}$ previamente determinada em camundongos de 18 a $20 \mathrm{~g}$, por via im '.

Antiveneno botrópico, lote 8905132 , produzido pelo IB.

Agulha e seringa apropriadas para injeção intradérmica ("agulha e seringa de tuberculina").

Camundongos brancos (Mus musculus) de 18 a 20g, sem distinção quanto a sexo, provenientes do biotérico central do IB.

\section{Mérodo}

Com o objetivo de comparar a sobrevida dos camundongos após 48 horas de observação, quando se administrava o antiveneno totalmente por via ip ou parte por via ip e parte por via im no local da inoculação de 2 DL50 do veneno imediatamente e 30 minutos após esta inoculação, realizaram-se os seguintes experimentos.

1 - Determinação da dose efetiva $50 \%$ do antiveneno "in vivo" administrado por via intraperitoneal imediatamente (DE50 0h) e 30' após (DE50 30') a inoculação im de 2 DL50 do veneno.
1-1. A DE50 oh foi determinada através da administração, a grupos de 8 camundongos (total de 40 camundongos sendo 8 para o controle do veneno), de diferentes volumes do antiveneno por via intraperitoneal, imediatamente após a inoculação de 2 DL50 do veneno por via intramuscular.

1-2. A DE50 $30^{\prime}$ foi determinada da mesma forma, com o mesmo número de camundongos, porém administrando-se o antiveneno $30 \mathrm{minu}$ tos após a inoculação do veneno.

2 - Determinação da eficácia da administração do antiveneno por via intramuscular, no mesmo local, imediatamente (DE50 Oh) e 30' após (DE50 30') a inoculação de 2 DL50 im do veneno.

2-1. Imediatamente após a inoculação por via im, de duas DL50 do veneno, a DE50 Oh do antiveneno foi administrada totalmente por via ip ( 40 camundongos) e $1 / 2$ por via ip e $1 / 2$ por via im no local da inoculação do veneno. (40 camundongos).

2-2. Trinta minutos após a inoculação por via im, de duas DL50 do veneno, a DE50 $30^{\prime}$ do antiveneno foi administrada totalmente por via ip (40 camundongos) e, $1 / 2$ por via ip e $1 / 2$ por via im no local da inoculação do veneno (40 camundongos).

O controle da atividade do veneno foi realizado inoculando-se duas DL50 do veneno, por via im, em 40 camundongos que não receberam antiveneno.

As injeções nos camundongos foram realizadas por via im, na face externa da coxa e, por via ip, através da parede abdominal, após antissepsia da pele.

A DE50 Oh e a DE50 30' foram calculadas pelo método estatístico de probitos e, para comparar os resultados obtidos com o antiveneno administrado somente por via ip com aqueles obtidos com sua administração por via ip e im, foi realizada análise estatística através do teste do $\mathrm{X}^{2}$.

\section{RESULTADOS}

1. As doses efetivas $50 \%$ do antiveneno "in vivo" administrado por via intraperitoneal imediatamete (DE50 0h) e 30 minutos após (DE50 30') a inoculação do veneno, foram de $0,01 \mathrm{ml} \mathrm{e} 0,03 \mathrm{ml}$, respectivamente (Tabelas 1 e 2 ). 
AGOSTINI UTESCHER, C. L.; VIEIRA, S. L.P.; FENSTERSEIFER, S.; RIBEIRO,L. A. \& JORGE,M.T. - Avaliação da eficácia do antiveneno botrópico administrado no local da inoculação intramuscular do veneno de Bothrops jararaca: estudo experimental em camundongos. Rev. Inst. Med. trop. S. Puulo, 36(3):275-278, 1994.

\section{TABELA 1}

Determinação da dose efetiva $50 \%$ do antiveneno botrópico administrado por via intraperitoneal imediatamente após a inoculação de 2 DL50 im do veneno de $B$. jararaca.

\begin{tabular}{lllll}
\hline $\begin{array}{c}\text { Antiveneno } \\
(\mathrm{ml})\end{array}$ & $\begin{array}{c}\text { Veneno } \\
\text { (DL) }\end{array}$ & $\mathrm{I}$ & $\begin{array}{c}\text { Experimentos } \\
\text { II }\end{array}$ & III \\
\hline 0,0017 & 2 & $1 / 8$ & $0 / 8$ & $0 / 8^{*}$ \\
0,0039 & 2 & $0 / 8$ & $1 / 8$ & $3 / 8$ \\
0,0088 & 2 & $4 / 8$ & $5 / 8$ & $3 / 8$ \\
0,0200 & 2 & $5 / 8$ & $5 / 8$ & $7 / 8$ \\
& 2 & $0 / 8$ & $0 / 8$ & $0 / 8^{* *}$ \\
\hline \multirow{2}{*}{ DE50(mI) } & & & & \\
\hline
\end{tabular}

* o denominador representa os camundongos do experimento e o numerador os que sobreviveram.; ** controle da atividade do veneno.; *** DE50 média foi de $0,0102 \mathrm{ml}$.

\section{TABELA 2}

Determinação da dose efetiva $50 \%$ do antiveneno bot rópico administrado por via intraperitoneal 30 minutos após a inoculação de 2 DL50im do veneno de $B$. jararaca.

\begin{tabular}{llcll}
\hline $\begin{array}{c}\text { Antiveneno } \\
(\mathrm{ml})\end{array}$ & $\begin{array}{c}\text { Veneno } \\
\text { (DL) }\end{array}$ & I & $\begin{array}{c}\text { Experimentos } \\
\text { II }\end{array}$ & III \\
\hline 0,0039 & 2 & $1 / 8$ & $0 / 8$ & $2 / 8^{*}$ \\
0,0088 & 2 & $2 / 8$ & $0 / 8$ & $1 / 8$ \\
0,0200 & 2 & $3 / 8$ & $2 / 8$ & $5 / 8$ \\
0,0450 & 2 & $6 / 8$ & $5 / 8$ & $5 / 8$ \\
- & 2 & $0 / 8$ & $0 / 8$ & $0 / 8^{* *}$ \\
\hline DE50(ml) & & 0,0221 & 0,0357 & $0,0228^{* * *}$ \\
\hline
\end{tabular}

* o denominador representa os camundongos do experimento e o numerador os que sobreviveram.; ${ }^{* *}$ controle da atividade do veneno.; *** DE50 média foi de $0,0268 \mathrm{~m}$ !

2-1. Não houve diferença estatisticamente significante nas taxas de mortalidade em 48 horas entre os dois grupos de camundongos que, imediatamente após a inoculação do veneno, receberam o antiveneno ( $p>0,05)$, embora houvesse tendência à maior sobrevida entre os que o receberam somente por via ip em relação àqueles que o receberam também por via im (Tabela 3).

2-2. Nos camundongos que, 30 minutos após o veneno, receberam $o$ antiveneno, houve maior proteção (menor taxa de mortalidade em 48 horas) no grupo que o recebeu apenas por via ip em relação àqueles que o receberam também por via im $(\mathrm{p}<0,05)$ (Tabela 3$)$.

\section{DISCUSSĀO}

No Brasil, os acidentes por serpentes peçonhentas são causados principalmente pelo gêneros Bothrops ${ }^{8}$. No Estado de São Paulo, onde o dado pode ser obtido com certa precisão, dentre 6.834 acidentes cujo diagnóstico foi realizado, $85,6 \%$ foram causados por Bothrops "1. B. jararaca é responsá vel por quase todos os casos de acidente botrópico atendidos no Hospital Vital Brazil (HVB) $^{10}$.

O único tratamento específico para o envenenamento botrópico é a administração do antiveneno, que deve ser realizada o mais precocemente possível. A via ev é a recomendada e a injeção no local da picada tem sido desaconselhada ${ }^{12}$. Não existem, entretanto, estudos comprovando a ineficácia da administração do antiveneno no local da inoculação do veneno de serpentes do gênero Bothrops.

Pelo presente estudo observa-se que, quando se administra $o$ antiveneno 30 minutos após a inoculação do veneno, para se obter o mesmo efeito da sua administração imediatamente após, há necessidade de maior quantidade de antiveneno. Quando se administra a metade da DE50 do antiveneno por via im, no local da

TABELA 3

Resultados da administração da DE50 do antiveneno botrópico, imediatamente após e 30' após a inoculação im de duas DLS0 do veneno de Bothrops jararaca, por via ip e, $1 / 2$ por via ip e $1 / 2 \mathrm{im}$, no local da inoculação do veneno.

\begin{tabular}{|c|c|c|c|}
\hline Ensaios & Sobreviventes & Óbitos & Total \\
\hline \multicolumn{4}{|l|}{ Grupo experimental $1-1(n=40)$} \\
\hline $2 \mathrm{DL} 50 \mathrm{im}+\mathrm{DE} 50 \mathrm{Oh}$ ip & 15 & 25 & 40 \\
\hline \multicolumn{4}{|l|}{ Grupo experimental $1-2(n=40)$} \\
\hline $\begin{array}{l}2 \mathrm{DL} 50 \mathrm{im}+\mathrm{DES} 0 \mathrm{Oh} \\
(1 / 2 \mathrm{ip}+1 / 2 \mathrm{im})\end{array}$ & 9 & 31 & $40^{*}$ \\
\hline \multicolumn{4}{|l|}{ Grupo experimental 2-1 $(n=40)$} \\
\hline 2DL50 im + DES0 $30^{\prime} \mathrm{ip}$ & 21 & 19 & 40 \\
\hline \multicolumn{4}{|l|}{ Grupo experimental $2-2(n=40)$} \\
\hline \multicolumn{4}{|l|}{$2 \mathrm{DL} 50 \mathrm{im}+\mathrm{DES} 530^{\prime}$} \\
\hline$(1 / 2 \mathrm{ip}+1 / 2 \mathrm{im})$ & 12 & 28 & $40 * *$ \\
\hline Controle do veneno $(n=40)$ & 00 & 40 & 40 \\
\hline Total & 57 & 143 & 200 \\
\hline
\end{tabular}

ip = intraperitoneal; im = intramuscular; DL50 - dose letal $50 \%$ do veneno por via im; DE50 = dose efetiva $50 \%$ do antiveneno por via ip, após inoculação de 2 DL50 do veneno, por via im.; * Não houve diferença estatisticamente significante $(p>0,05)$; ** Houve diferença estatisticamente significante $(p<0,05)$. 
AGOSTINI UTESCIER, C. L.; VIEIRA, S. L.P.; FENSTERSEIFER, S.; RIBEIRO,L. A. \& JORGE,M. T. - Avaliação da eficácia do antiveneno botrópico administrado no local da inoculação intra muscular do veneno de Bothrops jararaca: estudo experimental em camundongos. Rev. Inst. Med. trop. S. Paulo, 36(3):275-278, 1994.

inoculação do veneno, trinta minutos após este procedimento, a sobrevida dos camundongos é significantemente menor do que quando todo o volume é administrado por via ip. Vários, entretanto, sobreviveram. Em experimento anterior, quando o mesmo procedimento foi realizado com o veneno de $C$. d. terrificus e antiveneno crotálico ${ }^{9}$, nenhum camundongo do grupo que recebeu a metade do antiveneno por via im sobreviveu. Isto talvez se deva à diferença do veneno que, no caso do botrópico causa intensa destruição tecidual, o que pode dificultar a absorção do veneno inoculado e a difusão do antiveneno administrado por via ev.

A administração im do antiveneno imediatamente após a inoculação im do veneno, quando se presume que este não tenha sido completamente absorvido, também não levou a uma maior sobrevida dos camundongos.

Apesar de se ter avaliado apenas a evolução para o óbito (que pode ter causa diferente no envenenamento do camundongo e do homem) e não se ter avaliado o edema ou outros sinais de lesão tecidual, os resultados deste trabalho confirmam as recomendações de que o soro antibotrópico deva ser administrado, como o anticrotálico, apenas por via ev.

\section{SUMMARY}

\section{Assessment of the efficacy of antivenom injection at the site of the intramuscular inoculation of Bothrops jararaca venom in mice}

The $50 \%$ effective intraperitoneal (ip) dose of Bothrops jararaca antivenom (ED50) was assessed in mice immediately (ED50 Oh) and thirty minutes (ED50 $30^{\prime}$ ) after the intramuscular (im) injection of two $50 \%$ lethal dose (LD50) of Bothrops jararaca venom.

The efficacy of the antivenom injected at the venom inoculation site was assessed by the inoculation of two LD50 of the venom by im route, followed immediately (ED50 Oh) and 30 minutes later (ED50 30') by administration of the ED50 of the antivenom either entirely by the ip route or 50 percent ip plus 50 percent im, at the same inoculation site. It was shown that the EDS0 30' was 3 times greater, than the ED50 Oh and that the antivenom was more protective to mice (lower death rate in 48 hours) when given entirely ip. It was concluded that, in this experimental model, a higher dose of bothropic antivenom is needed when the treatment is started lately, and that there is no benefit in its administration at the venom inoculation site.

\section{REFERÊNCIAS BIBLIOGRÁFICAS}

1. AGOSTINT UTESCHER, C. L.; FENSTERSEIFER, S.; VIEIRA, S. L. P.; RIBEIRO, L. A. \& JORGE, M. T. - The estimation of the efficacy of Bothrops antivenom administration immediately and thirty minutes after the inoculation of $B$. jararaca venom. Toxicon, 31: 107, 1993.

2. BRAZIL, V. - A defesa contra o ophidismo. São Paulo, Pocai \& Weiss, 1911.

3. FONSECA, F. - Animais peçonhentos, São Paulo, Empresa Gráfíca da Revista dos Tribunais, 1949.

4. HAWGOOD, B. J. - Dr. Vital Brazil and the advent of antivenomous serotherapy. Toxicon, 31: 137-138, 1993.

5. JORGE, M. T. \& RIBEIRO, L. A. - Acidentes por animais peçonhentos. In: AMATO NETO, V. \& BALDY, J. L. S., ed. - Doenças transmissíveis. 3. ed. São Paulo, Sarvier, 1989. p. 133-141.

6. JORGE, M. T. \& RIBEIRO, L. A. - Acidentes por serpentes peçonhentas do Brasil. Rev. Ass. méd. bras., 36: 66-77, 1990.

7. MINISTÉRIO DA SAÚdE, CENTRO DE DOCUMENTAÇÃO DO MTNISTÉRIO DA SAÚDE - Manual de diagnóstico e tratamento de acidentes offdicos. Brasilia, 1987.

8. RESENDE, C. C.; ARAUJO, F. A. A. \& SALlENAVE, R. N. U. R. - Análise epidemiológica dos acidentes offdicos. Brasília, Ministério da Saúde; Secretaria Nacional de Açöes Bảsicas de Saúde, 1989.

9. RIBEIRO, L. A.; AGOSTTNI UTESCHER, C. L.; VIEIRA, S. L. P.; MUKUNO, H. \& JORGE M. T. - Avaliação em camundongo da eficácia do antiveneno administrado no local da inoculação intramuscular do veneno de Crotalus durissus terrificus. Rev. Inst. Med. trop. S. Paulo, 35: 23-27, 1993.

10. RIBEIRO, L. A. \& JORGE, M. T. - Epidemiologia e quadro clínico do acidente por Bothrops jararaca filhote e adulta. Rev. Inst. Med. trop. S. Paulo, 32: 436-442, 1990.

11. RIBEIRO, L. A.; PIRES DE CAMPOS, V. A. F.; ALBUQUERQUE, M. J. \& TAKAOKA, N. Y. - Acidente ofidico no Estado de São Paulo. Rev. Ass. méd. bras., 39: 4-7, 1993.

12. ROSENFELD, G. - Acidentes por animais peçonhentos; serpentes aranhas e escomiões. In: VERONESI, R., ed. - Doenças infecciosas e parasitárias. 8, ed. Rio de Janeiro, Guanabara Koogan, 1991. p. 951-962.

13. SECRETARIA DE ESTADO DA SAÚDE - Manual de vigilância epidemiológica: acidentes por animais peçonhentos, identificação, diagnóstico e tratamento. São Paulo, 1993.

14. WORLD HEALTH ORGANIZATION - Progress in the characterization of venoms and standardization of antivenoms. Geneva, World Health Organization, 1981. (WHO-Offet publ. n. 55).

Recebido para publicação $\mathrm{em} \mathrm{12/08/1993.}$ Aceito para publicação em $25 / 11 / 1993$. 